\title{
Outcome Portfolios as an Assessment Tool for ABET EC-2000
}

\author{
Ever J. Barbero, Larry E. Banta, Jacky C. Prucz and Charles F. Stanley \\ Mechanical and Aerospace Engineering, College of Engineering and Mineral \\ Resources, West Virginia University, Morgantown, WV 26506-6106
}

\begin{abstract}
A novel implementation of outcome portfolios is presented. Outcome portfolios is an assessment tool used by the authors to accomplish triangulation in the ABET EC-2000 assessment process. Systematic and effective use of outcome portfolios has provided us with a convenient, reliable, and powerful tool for assessing the level of achievement of our graduates on all the program outcomes for the Aerospace Engineering and Mechanical Engineering programs at West Virginia University. The new system and its implementation into the assessment process are discussed here. Assessment data is presented to support the hypothesis that survey data alone is inconclusive and that outcome portfolios provide additional, valuable information for program enhancement. A comparison between the data for the two programs, Aerospace Engineering and Mechanical Engineering, is used to support our conclusions.
\end{abstract}

\section{Introduction}

Both the Aerospace Engineering (AE) and Mechanical Engineering (ME) programs at West Virginia University are administered in the Department of Mechanical and Aerospace Engineering (MAE) and have been accredited programs for a long time. Our last ABET visit under the old accreditation criteria took place in 1997. It resulted in a six-year review recommendation. In preparation for our first review under the EC 2000 criteria in Fall 2003, the department implemented a comprehensive assessment process to satisfy criteria 2 and 3 [1-3]. Three or more tools are necessary to accomplish triangulation [1]. Although surveys of various types are the most popular tools for assessment, they are subjective, and over-reliance on them may be misleading. Alternative tools such as standardized examinations, interviews, and focus groups tend to be costly in time and resources. The objective of this paper is to describe our approach to assembling, assessing, and improving outcome portfolios [4], as an essential assessment tool for outcome assessment under criteria 3. 


\section{Outcome Portfolios}

Using outcome portfolios is an idea that evolved from the compilation of course portfolios, a practice that is traditional in our department. An outcome portfolio is assembled separately for each program outcome by compiling evidence of student work related to that particular outcome from material that is routinely collected and assembled in the form of course portfolios. Every instructor develops a course portfolio for every course that he teaches in a given semester by collecting a mix of student work, instructor lecture notes, handouts, and other materials. All of aforementioned materials are important to the curriculum committee in assessing course content and plotting general pedagogical strategy. However, EC-2000 requires that evidence of student achievement of the outcomes be based predominantly on examples of student work.

Physically, an outcome portfolio is a 3-ring binder with several sections for materials that support the assessment of the outcome. The outcomes of both the AE and ME program follow closely the eleven outcomes (a) through (k) suggested by EC 2000, with the exception that the ME program has an additional outcome:

"(L) Graduates will possess an ability to use modern microprocessors, microcontrollers, sensors, and actuators in mechatronics systems designed to monitor and control products and processes."

For each outcome, an outcome portfolio is assembled as part of the assessment process. Each outcome portfolio is updated at the end of the spring semester each academic year, and contains the following sections/materials:

- Outcome Statement

- Goals

- Educational strategy

- Course Matrix

- Key courses

- Assessment Team Findings

- Evidence gathered from key course portfolios

- Scores for each goal/course

- Summary Statement and recommendations

\section{Goals}

In addition to slightly modifying the one-sentence definitions suggested by EC 2000 for outcomes (a) through (k), the faculty developed more extensive and specific definitions that reflect their interpretation of each outcome. The refined definition of the outcomes is contained in the educational strategy for each outcome (see next Section). In developing our outcomes definitions, it became apparent that the EC 2000 definitions for most outcomes were broad and difficult to measure. Also, we realized that many of the outcomes could be subdivided into two or three sub-outcomes, which we called goals. Goals not only allow for a more specific, tangible interpretation of outcomes, but more importantly they facilitate the evaluation of the data provided by the assessment tools. Each goal is defined in a paragraph, such as the following, 
Outcome (g): Graduates will have an ability to communicate effectively.

Goal 1: Graduates will be able to demonstrate effective oral communication.

Goal 2:Graduates will be able to demonstrate effective written communication.

\section{Educational Strategy}

Once the outcomes were defined and measurable goals were identified, we mapped out an educational strategy for each outcome. The educational strategy describes our specific interpretation of each outcome and it outlines the general curricular approach and a sequence of courses to ensure that all students attain, by graduation, the skills required for each outcome. An example of an educational strategy statement follows,

Outcome (d): Graduates will have an ability to function on multi-disciplinary teams.

I. Educational Strategy - Description of Approach to Reach the Outcome

Engineering education is changing from the narrow engineering science curriculum to a broader industry-driven curriculum. Today's employers are seeking engineering graduates with the ability to work effectively in team-based environments. The Mechanical Engineering curriculum prepares our undergraduates to work in teaming environments in at least two ways: 1) through design projects that require the application of different technical areas of mechanical engineering and 2) through projects and courses that have students from different majors working together.

One may notice that other definitions of multi-disciplinary could be adopted but the one presented above is the definition that our faculty decided to pursue. These definitions are published and communicated to our students through pertinent course syllabi, the department web page, and by the instructors of related courses. The purpose is to ensure that our students know what we are trying to accomplish, what skills we expect them to acquire, and what is the meaning of each outcome in the context of the Aerospace Engineering and Mechanical Engineering programs at West Virginia University.

\section{Key Courses and Curriculum Mapping}

In order to minimize the faculty workload associated with compilation and assessment of outcome portfolios, the curriculum committee of each program (AE and ME) identified a set of key courses for each outcome, similar to the concept of target courses in [4]. Key courses for a given outcome are those courses that the curriculum committee has determined are most likely to display evidence of student work that can be used to assess that outcome. For example, the following are the key courses for outcome $(\mathrm{g})$ of the ME program:

Outcome (g) Graduates will have the ability to communicate effectively 
MAE 244 - Dynamics and Strength Laboratory: In this one-credit-hour sophomore-level course, students are required to write and submit laboratory reports for each one of the eight experiments carried out in this class. While grading the reports, the instructor provides feedback to the students and a steady improvement in written communication is expected.

MAE 322 - Thermal and Fluids Lab: In this one-credit-hour junior-level course, teams of students are assigned projects, which require them to turn in project reports and make presentations to the rest of the class and the instructor.

MAE 456 - CAD and Finite Element Analysis: In this three-credit-hour seniorlevel course, teams of students are assigned projects, which require them to turn in project reports and make presentations to the rest of the class and the instructor.

MAE 471 - Principles of Engineering Design: This capstone design class typically has several sections, however all sections are required to have a strong writing component including feedback and coaching on each student's writing per se. Students prepare resumes, project progress memos, design reports, project proposals and other written communications as the instructor sees fit. Most sections also include oral presentations.

It is important to note that the key courses identified for a particular outcome are not by any means the only courses that contribute to developing the skills students need to master the outcome. The evidence is collected from a few key courses but the ability of our students to achieve an outcome is developed over a large set of related courses ( $\mathrm{R}$ in Table 1). Thus, program enhancement requires that all opportunities for improvement be considered. Therefore, all related courses and key courses are identified in a curriculum-mapping matrix that displays all of the interactions among courses and outcomes (Table 1). The curriculum-mapping matrix is very useful in making sure that all outcomes are adequately supported by the curriculum and that the syllabus for each course includes appropriate learning objectives to support the relevant outcomes.

\section{Assessment Team Findings}

Once approved by the faculty, the materials described thus far are included in the outcome portfolios as boilerplate to standardize the assessment process by providing clear and measurable definitions of the outcomes and standard locations for assessment teams to look for evidence. The educational strategy statement provides context for the selection of evidence and the assessment thereof. But the bulk of the material in a complete outcome portfolio derives from the assessment process itself. That process will be described next. 
Table 1. Curriculum-mapping matrix for the ME program. $R=$ related course, $K=$ key course.

\begin{tabular}{|c|c|c|c|c|c|c|c|c|c|c|c|c|}
\hline Required course & $\mathbf{A}$ & $\mathbf{B}$ & $\mathbf{C}$ & D & $\mathbf{E}$ & $\mathbf{F}$ & $\mathbf{G}$ & $\mathbf{H}$ & I & $\mathbf{J}$ & $\mathbf{K}$ & $\mathbf{L}$ \\
\hline Chemistry 115 Fund. Of Chemistry & $\mathrm{R}$ & $\mathrm{R}$ & & & & $\mathrm{R}$ & & & & & & \\
\hline Math 155 Calculus 1 & $\mathrm{R}$ & & & & & & & & $\mathrm{R}$ & & & \\
\hline Engineering. 101 Fresh. Engr. Design & & & $\mathrm{R}$ & & $\mathrm{R}$ & $\mathrm{R}$ & $\mathrm{R}$ & & $\mathrm{R}$ & & & \\
\hline English 101 Composition and Rhetoric & & & & & & & $\mathrm{R}$ & & & & & \\
\hline Math 156 Calculus 2 & $\mathrm{R}$ & & & & & & & & $\mathrm{R}$ & & & \\
\hline Engineering 102 Fresh. Engr. Design \& Analysis & $\mathrm{R}$ & & $\mathrm{R}$ & & $\mathrm{R}$ & & & & & & & \\
\hline Physics 111 General Physic Lab & $\mathrm{R}$ & $\mathrm{R}$ & & & $\mathrm{R}$ & & $\mathrm{R}$ & & & & & \\
\hline MAE 211 Mechatronics & $\mathrm{R}$ & $\mathrm{K}$ & $\mathrm{K}$ & $\mathrm{K}$ & $\mathrm{R}$ & $\mathrm{K}$ & $\mathrm{R}$ & & $\mathrm{R}$ & & $\mathrm{K}$ & $\mathrm{K}$ \\
\hline MAE 241 Statics & $\mathrm{R}$ & & & & $\mathrm{R}$ & & & & & & & \\
\hline Math 251 Multivariable Calculus & $\mathrm{R}$ & & & & & & & & & & & \\
\hline Physics 112 General Physics and Lab & $\mathrm{R}$ & & & & $\mathrm{R}$ & & $\mathrm{R}$ & & $\mathrm{R}$ & & & \\
\hline English 102 Composition \& Rhetoric & & & & & & & $\mathrm{R}$ & & $\mathrm{R}$ & & & \\
\hline MAE 242 Dynamics & $\mathrm{R}$ & & & & $\mathrm{R}$ & & & & $\mathrm{R}$ & & & \\
\hline MAE 243 Mech. Of Materials & $\mathrm{R}$ & & & & $\mathrm{R}$ & & & & $\mathrm{R}$ & & & \\
\hline MAE 261 Elem. Diff. Equations & $\mathrm{R}$ & & & & & & & & $\mathrm{R}$ & & & \\
\hline MAE 244 Dynam, \& Strength Lab & $\mathrm{R}$ & $\mathrm{K}$ & & & $\mathrm{R}$ & $\mathrm{K}$ & $\mathrm{K}$ & & & & $\mathrm{R}$ & $\mathrm{R}$ \\
\hline MAE 320 Thermodynamics & $\mathrm{R}$ & & & & $\mathrm{R}$ & & & & $\mathrm{R}$ & & & \\
\hline MAE 331 Fluid Mechanics & $\mathrm{R}$ & & & & $\mathrm{R}$ & & & & $\mathrm{R}$ & & & \\
\hline MAE 343 Intermed. Mech. Of Materials & $\mathrm{K}$ & & $\mathrm{K}$ & & $\mathrm{R}$ & & & & & & $\mathrm{R}$ & \\
\hline EE 306 Basic Electrical Engr. & $\mathrm{R}$ & & $\mathrm{R}$ & & $\mathrm{R}$ & & & & & & & $\mathrm{R}$ \\
\hline EE 307 Basic Electrical Lab & $\mathrm{R}$ & $\mathrm{R}$ & $\mathrm{R}$ & & & & & & & & & $\mathrm{R}$ \\
\hline MAE 316 Analysis Of Engr. Systems & $\mathrm{K}$ & $\mathrm{R}$ & & & $\mathrm{R}$ & & & & & & $\mathrm{R}$ & \\
\hline MAE 321 Applied Thermodynamics & K & & & & $\mathrm{R}$ & & & & & & & \\
\hline MAE 322 Thermal and Fluids Lab & $\mathrm{R}$ & $\mathrm{K}$ & & & $\mathrm{R}$ & & $\mathrm{K}$ & & & & $\mathrm{K}$ & $\mathrm{R}$ \\
\hline MAE 342 Dynamics of Machines & $\mathrm{R}$ & & $\mathrm{R}$ & & $\mathrm{R}$ & & $\mathrm{R}$ & & & & & \\
\hline IMSE 302 Manufacturing Processes & $\mathrm{R}$ & & $\mathrm{R}$ & $\mathrm{R}$ & $\mathrm{R}$ & & & & & & & \\
\hline IMSE Manufacturing Proc. Lab & $\mathrm{R}$ & $\mathrm{R}$ & $\mathrm{R}$ & $\mathrm{R}$ & & & $\mathrm{R}$ & & & & & \\
\hline MAE 411 Advanced Mechatronics \& Lab & $\mathrm{R}$ & $\mathrm{K}$ & $\mathrm{R}$ & & $\mathrm{R}$ & & $\mathrm{R}$ & & & & $\mathrm{R}$ & $\mathrm{K}$ \\
\hline MAE 423 Heat Transfer & $\mathrm{R}$ & & $\mathrm{R}$ & & $\mathrm{R}$ & & $\mathrm{R}$ & & & $\mathrm{K}$ & & \\
\hline MAE 454 Machine Design and Mfg. & $\mathrm{R}$ & & $\mathrm{K}$ & & $\mathrm{K}$ & & $\mathrm{R}$ & & $\mathrm{K}$ & $\mathrm{K}$ & & \\
\hline MAE 456 CAD and Finite Ele. Anaylsis & $\mathrm{R}$ & & $\mathrm{K}$ & & $\mathrm{K}$ & & $\mathrm{K}$ & & & & $\mathrm{K}$ & \\
\hline MAE 460 Automatic Controls & $\mathrm{R}$ & & $\mathrm{K}$ & & $\mathrm{K}$ & & & & & & $\mathrm{R}$ & $\mathrm{R}$ \\
\hline MAE 471 Principles of Engr. Design & $\mathrm{R}$ & $\mathrm{R}$ & $\mathrm{K}$ & $\mathrm{K}$ & $\mathrm{R}$ & $\mathrm{K}$ & $\mathrm{K}$ & $\mathrm{K}$ & $\mathrm{K}$ & $\mathrm{K}$ & $\mathrm{K}$ & \\
\hline Cluster A (12 hours) & & & & & & & $\mathrm{R}$ & $\mathrm{R}$ & & & & \\
\hline Cluster B (12 hours) & & & & & & & $\mathrm{R}$ & $\mathrm{R}$ & & $\mathrm{R}$ & & \\
\hline Technical Electives (6 hours) & & & & & & & & & $\mathrm{R}$ & & & \\
\hline ENGR 199 Orientation to Engineering & & & & & & $\mathrm{R}$ & & $\mathrm{R}$ & $\mathrm{R}$ & $\mathrm{R}$ & & \\
\hline
\end{tabular}




\section{Assessment Teams}

Rather than assigning the responsibility for assessment to a committee, we decided to engage the entire faculty in the assessment process. We set up twelve assessment teams, one for each outcome. Each team consists of two faculty members who volunteer to analyze a given outcome and to become the "advocates" for that outcome. Being an advocate means promoting improvements of the assessment process and of the educational programs to achieve continued improvement in the student achievement of the outcome. Each team assesses both the AE and ME programs, except the team for outcome (1), which has only the ME program to assess. This system guarantees participation and ownership of the assessment process by the entire faculty. An effort is made to avoid assigning the instructors of the key courses for a given outcome to the assessment team for that outcome. This approach enhances the objectivity of the process and also enhances the knowledge of the curriculum among the faculty - every faculty member has the opportunity to learn in detail what other instructors are doing in their classes.

\section{Collection of Evidence: Course Portfolios}

Each semester, each instructor assembles a course portfolio for each section of each course he/she teaches. The course portfolios document the conduct of the class and the performance of the students for that section/semester. They are the primary source of evidence for constructing the outcome portfolios. Typically, the course portfolio will include the syllabus, copies of major handout materials, perhaps instructor lecture notes, and copies of student work of all types. Usually the instructor will choose five students whose work will be collected for the entire semester. Our standard practice for a class with $\mathrm{N}$ students is to choose the first, last, $\mathrm{N} / 4^{\text {th }}$, $\mathrm{N} / 2$ th, and $3 \mathrm{~N} / 4^{\text {th }}$ students from the roster. All of the work submitted by these students is photocopied before it is returned after grading. If one of the "sample" students drops the class, one of his/her "neighbors" on the roster is chosen by the instructor to collect. In this way, we collect a pseudorandom sample of work from each class, with the potential to look for evidence of student improvement during the course of the semester.

\section{Analysis of the Evidence: Outcome Portfolios}

The department provides each team a 3-ring binder for each program outcome assigned to the team. The binders contain a set of dividers for the boilerplate materials and for each goal and each key course. The teams examine the materials in the portfolios, looking for evidence to demonstrate student achievement of the outcome goals. Evidence in this case consists almost entirely of examples of student work: exams, homework assignments, lab or project reports, etc. The team may examine the syllabus, handouts or other materials to get a more comprehensive picture of the course and its conduct, but only student work is "admissible" as evidence for the outcome. This practice often leads to suggestions for improving assessment instruments within the course to better document student achievement in specific areas related to the outcomes. Since more than one team may use a given course portfolio, the teams must photocopy any evidence they find in the course portfolios, leaving the latter intact. The copies of the evidence are then inserted into the outcome portfolio in the appropriate place according to the dividers provided. Then, the assessment team evaluates the evidence according to a standard rubric. 


\section{Rubrics}

The faculty designed a standard rubric for all outcomes, based on a scale from 1 to 5 , as follows:

$1=$ no evidence that the goal was achieved,

$2=$ limited evidence that the goal was achieved,

$3=$ adequate evidence to demonstrate that the goal was achieved,

$4=$ the evidence is more than adequate to demonstrate that the goal was achieved, and

$5=$ substantial evidence that the goal was achieved.

NAp = Not Applicable: this course does not pertain to this particular goal. Examples would be courses that demonstrate writing skills but not oral communications skills, or familiarity with modern software, but not with modern laboratory or test equipment.

Each assessment team may customize the rubric slightly if necessary to fit its particular outcome as long as it does not contradict the default rubric (e.g., the scale 1-5 could not be altered). The 15 scale is set up to facilitate comparison with data from other assessment tools, such as surveys and questionnaires, described later in this paper.

\section{Assessment Team Summary and Recommendations}

The quantitative results generated by each assessment team are captured in a table with a score for each goal/course combination and a composite score calculated for each goal by averaging the scores from the individual courses, as shown in Table 2. The team also writes a prose summary of its findings, providing rationale for the scores assigned and pointing out particularly strong or weak aspects of the evidence for each key course and outcome. Their summary concludes with suggestions for improvements in either the course content, the assessment practices used in the course, or the selection of key courses for the outcome. Occasionally, suggestions arise for revision of the definitions of the goals for the outcome. The summary statement is included in the outcome portfolio, and is also presented orally to the faculty at large as part of the loop closing process described later.

Table 2. Course, Goal, and Outcome Score Table for Outcome (k), Spring 2003.

\begin{tabular}{|l|l|l|l|l|}
\hline Course & Goal 1 & Goal 2 & Average & Comment \\
\hline MAE 244 & 4.0 & Nap & 4.0 & Higher \\
\hline MAE 316 & 1.5 & 4.0 & 2.75 & No Change \\
\hline MAE 365 & 1.5 & 4.0 & 2.75 & Higher \\
\hline MAE 456 & NAp & 3.0 & 3.0 & No Change \\
\hline Average Outcome (k) & 2.3 & 3.7 & 3.0 & Higher \\
\hline
\end{tabular}

NAp. Not Applicable. 


\section{Assessment In the Broader Context}

The outcome portfolios represent only one source of assessment data, and by themselves cannot provide conclusive evaluation of a program's effectiveness. Other assessment tools available are [1]:

- Written Surveys and questionnaires

- Exit and other Interviews

- Commercial, norm-referenced, standardized examinations

- Locally developed examinations

- Archival records

- Focus groups

- Portfolios

- Simulations

- Performance appraisals

- External examiners

- Oral examinations

- Behavioral observations

The most popular of these are the surveys and questionnaires because they are relatively inexpensive and easy to implement. Even before EC 2002 was implemented, the department had a tradition of conducting several types of surveys and interviews:

1. Exit surveys. The university administers the exit surveys using a questionnaire designed differently for each college, in our case for the College of Engineering and Mineral Resources (CEMR). The exit survey is given to graduating seniors at the end of the fall and spring semesters. In years past, the questions did not match properly with the outcomes, but lately modifications were introduced to the survey to reflect the outcomes pursued by most engineering disciplines within the college. We have historically achieved about $60 \%$ response from graduating seniors, but recent directives from the administration "encourage" faculty to allow class time for completion of the survey in an attempt to improve the return rate.

2. Alumni Surveys. The department mails alumni surveys to recent graduates. The surveys are anonymous and can be completed on the web or by returning the paper survey. A unique password is mailed to each alumnus to preclude multiple responses or unauthorized responses. To prevent burnout of our graduates, we mail them to alumni having graduated 1, 3 , and 5 years before the current year. We achieve about $20 \%$ response from the alumni.

3. Employer Surveys. The department mails the employer surveys to recent graduates with a request to pass the surveys along to their employer. The surveys are anonymous and can be completed on the web or by returning the paper survey. A unique password is mailed to each employer surveyed to preclude multiple responses or unauthorized responses. We mail them to alumni having graduated 2, 4, and 6 years before the current year. We achieve about $15 \%$ response from employers.

4. Current Student Surveys. In the past, the department administered student surveys to all sophomore, junior, and senior students. These are burdensome and do not assess well the outcomes, which are loosely defined as "what the students will be able to achieve at 
graduation," because a large number of sophomores and juniors are being queried. They are no longer routinely used for ABET assessments, although we occasionally use them to gain other information.

5. Student Interviews. The departmental advisory committee administers student interviews, without faculty or administrators present, to a sample of students during a yearly meeting. The Advisory Committee summarizes the results of these interviews for the department.

6. Student Evaluation of Instruction (SEI). These are instruments to evaluate the quality of instruction and are not currently used in the ABET assessment process. However, the departmental administration and sometimes by the curriculum committee uses the results for assessment of instructor efficacy, student attitudes/perceptions regarding course quality, and so on.

\section{Triangulation}

The data from a single assessment tool may be misleading for a number of reasons [3]. A second tool can be used to provide confirmation but, if the data from the second tool are contradictory, it is difficult to decide which data to use. Data from a third tool usually provide confirmation for at least one of the other tools. Initially we used three surveys (listed as 1, 2, and 3 in the previous section) as the three pieces of data used to triangulate results but soon it became evident that using only surveys had its limitations. Without generalizing, one might say that surveys tend to paint a bland picture of the programs. There were a few exceptions for which the surveys indicated a weakness that we already knew about, but in general they failed to provide sufficient contrast. For example, the results of three survey tools (exit, alumni, and employer surveys) are very similar for every outcome, as shown in Fig. 1 for the AE program and Fig. 2 for the ME program. Also, the surveys show little variation among outcomes. While this could be due to a consistent and above average program, it is also possible that self-evaluations tend to reinforce the idea that "all children are above average".

The outcome portfolios provide a different perspective than do the surveys, and are an important component in the triangulation process. In the AE program, the survey scores are clustered around 3.5 (Fig. 1). In the ME program, the survey scores are also clustered (Fig. 2). The scores from outcome portfolios show more variation. The variations in the results of the outcome portfolio assessment were, in the beginning, sometimes the product of inconsistent assessment standards or inadequate evidence collection. However, most of those problems have been solved and we now feel that the portfolio assessment process has evolved to become a trustworthy data point for inclusion in the triangulation process.

Clearly, the scores from surveys and portfolios do not always coincide. In general, an average score is computed with equal weighting of all of the available inputs. If a large discrepancy exists among certain pieces of the data, we attempt to understand the reasons. In some cases, the discrepancy can be explained and a conclusion easily reached. An example is the scores for outcome (1) in the ME program, where the alumni surveys rated the program low and the faculty assessment teams rated it highly. The Mechatronics component of the ME program is only three years old, and most of the alumni had no exposure to it. In other cases, the differences are simply differences in perspective between students, employers, and faculty. 
When discrepancy cannot be rationalized, the faculty leans toward using the lowest score to decide if corrective actions should be implemented. This is particularly the case when the low score originates in the portfolios, because usually there is hard evidence to support the low score. A typical example are the results of outcomes (f) and (g) in the ME program (Fig. 2 and Table 3). Although the surveys yield acceptable scores, namely greater than 3 , the evidence of student work analyzed by the faculty do not support such scores. Therefore, the faculty used the low scores to justify implementation of corrective actions. Such corrective actions resulted in a marked improvement during Spring 2003, the first semester of its implementation, as shown in Table 3.

When outcome portfolios yield scores higher than surveys, the faculty leans toward averaging them. A typical example is the scores for outcome (e) in the AE program (Fig. 1). A high score from outcome portfolios is supported by the exit surveys but the alumni and employer surveys yield only an acceptable score. In a situation like this, all the scores are usually averaged.

Although an overall score is sought for the outcome, the individual goal scores contain useful information because they better pinpoint problems in the curriculum. Also, the insight from assessment teams is very valuable because they have observed the evidence of student work first hand and therefore can make sound recommendations for program enhancement.

Table 3. Example Analysis of Assessment Scores

\begin{tabular}{|l|c|c|c|}
\hline Assessment Tool, Outcome (F) & Goal 1 & Goal 2 & Average \\
\hline Spring 2002 Exit Survey & NA & NA & \\
\hline Fall 2002 Exit Survey & NA & NA & \\
\hline 2001-2002 Current Student Survey, 210 replies & 3.1 & 3.1 & 3.1 \\
\hline 2002 Alumni Survey, 28 replies & 3.5 & 3.5 & 3.5 \\
\hline 2002 Employer Survey, 21 replies & 3.7 & 4.0 & 3.9 \\
\hline Spring 2002 outcome portfolio & 3.3 & 2.3 & 2.8 \\
\hline Fall 2002 outcome portfolio & 3.6 & 2.0 & 2.8 \\
\hline 2002 Overall Score & & & $\mathbf{3 . 2 2}$ \\
\hline Spring 2003 outcome portfolio & 3.7 & 3.5 & 3.6 \\
\hline
\end{tabular}

\section{Closing the Loop}

The faculty at large formulates strategies for corrective action. Immediately following the assembly of the outcome portfolios, a faculty meeting is called. The department administration assembles a table like Table 3 for each outcome. The table is presented and each assessment team is required to deliver an oral summary of its findings from the outcome portfolio assessment process. The observations and recommendations of the assessment team are considered along with the data from the other sources and a conclusion is drawn regarding the need for and the form of corrective action. Simple cases can often be decided in the meeting by consensus. More difficult cases are referred to the appropriate curriculum committee for consideration and study. The curriculum committee then makes recommendations that, if substantive changes are involved, must be approved by the faculty. 
While immediate attention and resources are directed to problem areas, we strive to achieve continuous improvement of all outcomes. That means that a stagnant or declining score is a cause of concern regardless of the absolute score. Of course, scores below 3.0, or declining scores nearing 3.0 are causes of major concern and thus are addressed immediately and vigorously. Also, individual goals having low or declining scores are a cause of concern even if the aggregate score for the outcome is not low.

\section{Conclusions}

Outcome portfolios have been used successfully as a source of data in triangulating assessment scores. In our experience, outcome portfolios show more markedly the strengths and weaknesses of the programs than do alumni or other surveys. In addition, the process provides very valuable information in the form of goal scores that can be used readily for program enhancement in specific areas. Portfolio analysis provides rich insight into the actual performance of the students in the context of the program at large as portrayed by the program educational outcomes.

Since compilation and evaluation of outcome portfolios involves the majority of the faculty, it fosters a shared understanding of the entire program. This is in stark contrast with analysis of survey data, which tend to be performed by a single individual and only reported to the faculty. The use of assessment teams not only engages the faculty in assessing the outcomes, but also in refining the assessment process. For example, professors have provided suggestions for alternative and more appropriate key courses than those originally selected, and have provided clarifications or suggestions for modifications of outcome or goal definitions. Such changes were presented to the faculty at large, approved, and made integral part of the assessment process. Another advantage of formalizing the process in this way is that new faculty members can be integrated into the teams seamlessly.

Finally, since our department administers two programs, outcome portfolio assessment provides a useful tool to understand the differences between these programs. Such comparison highlights opportunities for program improvement by drawing on the strengths of each program.

\section{Bibliography}

1. ABET Continuous Program Improvement, Faculty Development Workshop, Montreal, Canada, June 2002.

2. Accreditation Board for Engineering and Technology, "Engineering Criteria 2000", in How do you measure success, ASEE Professional Books, 1998, pp. 13-16.

3. Soundarajan, Neelam, "Preparing for Accreditation Under EC 2000: An Experience Report", Journal of Engineering Education, January 2002, pp. $117-123$.

4. Morgan, S.M., Bradford Cross, W., Rossow, M.P., "Innovative outcome portfolios for ABET Assessment", presented at the ASEE Annual Conference, Session 2251, Albuquerque, NM, June 2000.

\section{Biographies}

Ever J. Barbero, ASME Fellow, is Professor and Chairman, Mechanical and Aerospace Engineering, College of Engineering and Mineral Resources at West Virginia University. He is recognized internationally for his work on 
material models for composite materials. He is the author of "Introduction to Composite Materials Design," published by Taylor and Francis (1999), over 80 peer-reviewed publications, numerous conference papers, and mentor of numerous MS and Ph.D. graduates currently serving leadership positions in academia and industry worldwide. He holds two US Patents, \#6,455,131 (2002) and \#6,544,624 (2003). He received the AE Alumni Academy Award for Outstanding Teaching (1999) and numerous research awards.

Larry E. Banta is Associate Professor and Associate Chairman of the Mechanical and Aerospace Engineering Department at West Virginia University. He has taught a wide array of courses at both the undergraduate and graduate levels and has won numerous teaching awards at the department, college and university levels. His current administrative duties include responsibility for undergraduate programs in the MAE Department. Dr. Banta has directed nearly $\$ 3$ million in externally funded research, primarily in the areas of industrial energy conservation, robotics and factory automation. He has published extensively on those topics and on various aspects of engineering education.

Jacky C. Prucz is an Associate Professor of Mechanical and Aerospace Engineering (MAE), who also holds the administrative position of Associate Chairman for Graduate Programs and Research in the MAE department. He joined the department in 1985, after earning the Ph.D. degree in Aerospace Engineering from Georgia Institute of Technology. Dr. Prucz has taught a wide variety of engineering courses, both at the undergraduate and the graduate levels, on topics ranging from freshman engineering design to senior design projects of aircraft and space systems. His primary area of research interest and expertise is application development of composite materials, and is currently responsible for research contracts dealing with effective applications of composite materials in jet engines, heavy ground vehicles, and infrastructure. He has published extensively and has been recognized for his accomplishments on many occasions and in various forums, including his selections as Outstanding Researcher (for the year 1989) and Outstanding Teacher (for the year 2002) of the College of Engineering and Mineral Resources.

Charles F. Stanley is a Professor of Mechanical and Aerospace Engineering within the College of Engineering and Mineral Resources at West Virginia University. He has taught graduate and undergraduate courses in the areas of Instrumentation, Engineering Design, and Engineering Mechanics. He has published extensively in Biomedical Engineering, his principal area of research. 


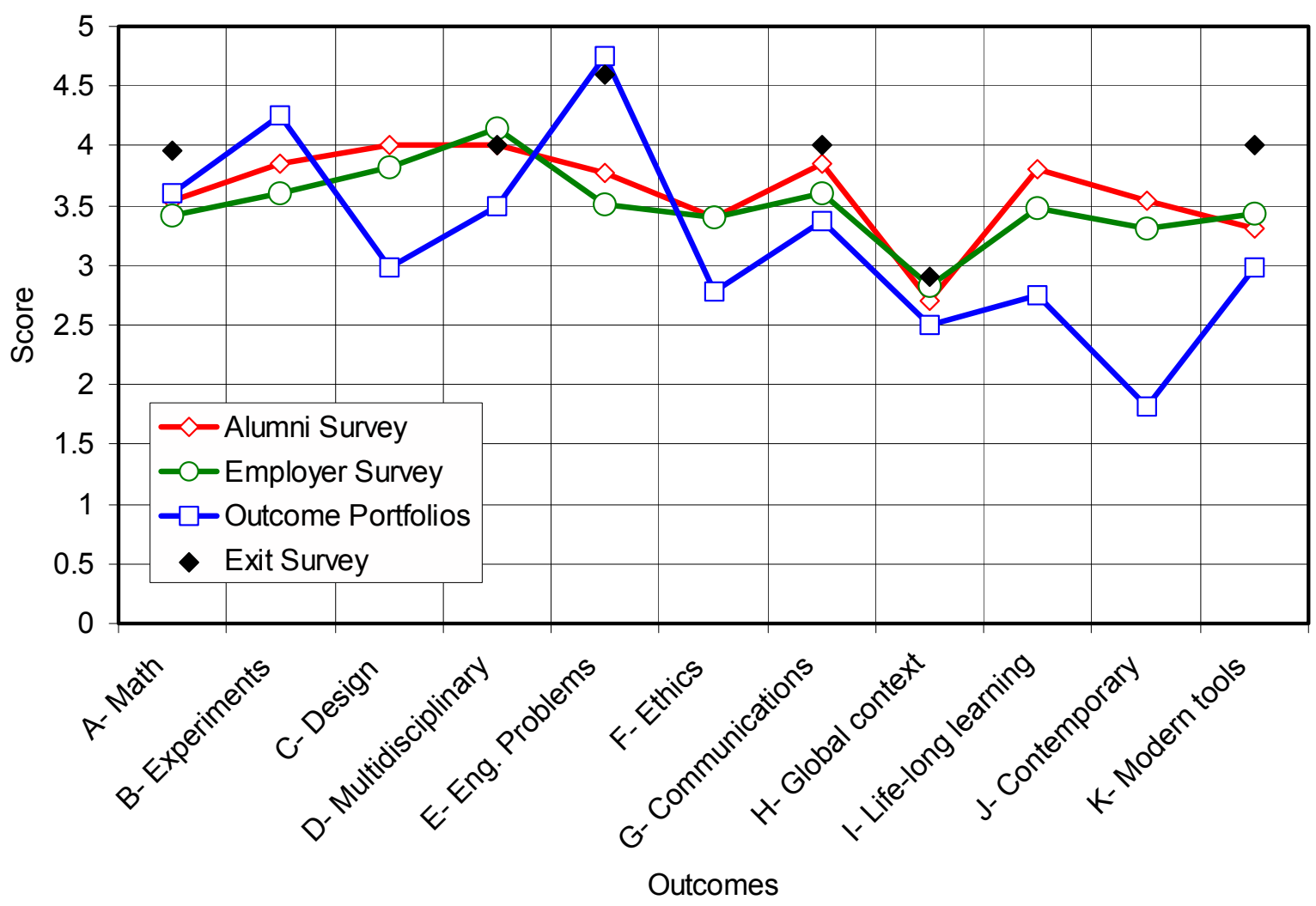

Figure 1. AE outcome assessment calendar year 2002

$$
\begin{aligned}
& \text { ญి } \\
& 0 \\
& \text { ڤั } \\
& \vec{\omega}
\end{aligned}
$$




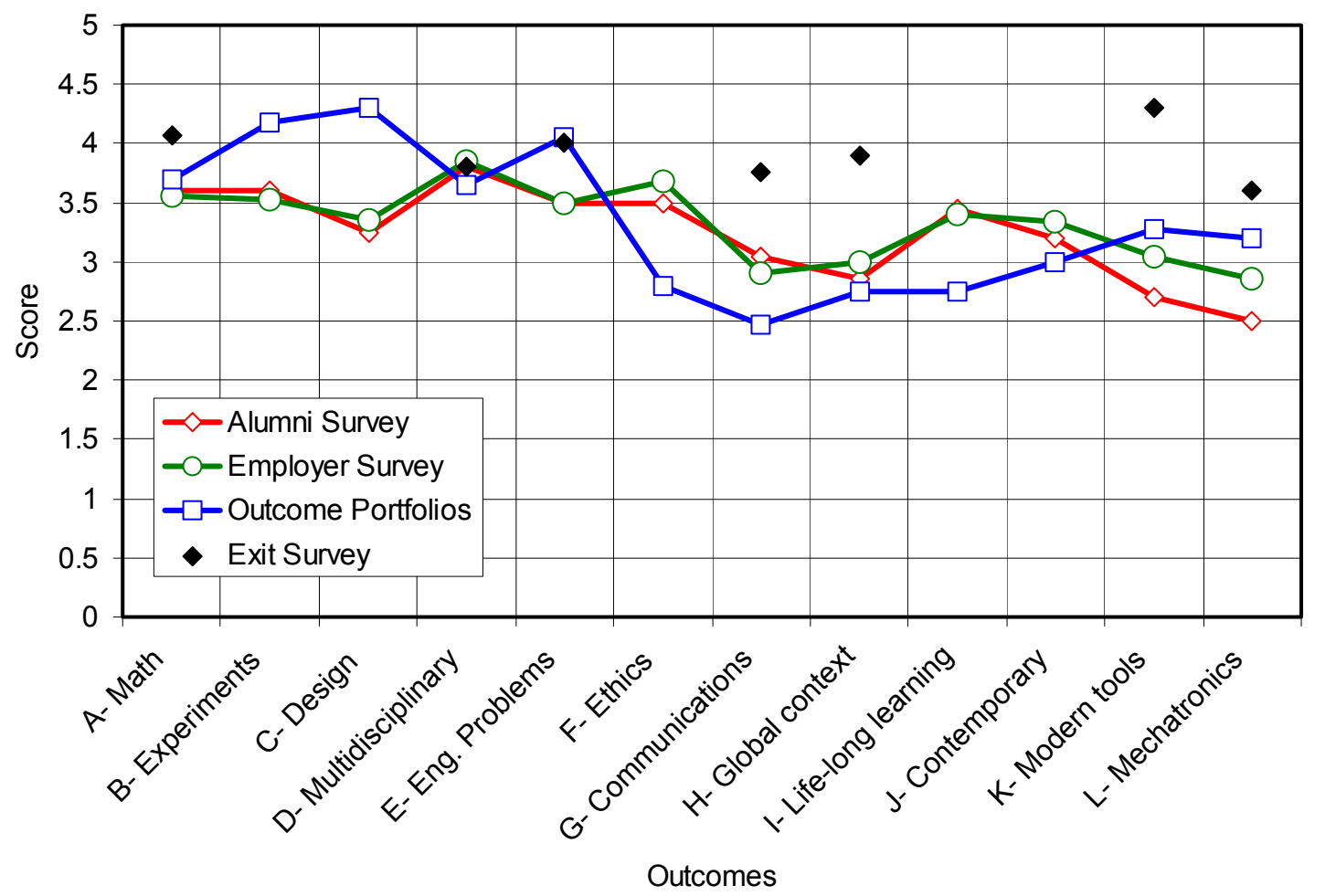

Figure 2. ME outcome assessment calendar year 2002.

$$
\begin{aligned}
& \text { อి } \\
& 0 \\
& \text { ڤั } \\
& \vec{A}
\end{aligned}
$$




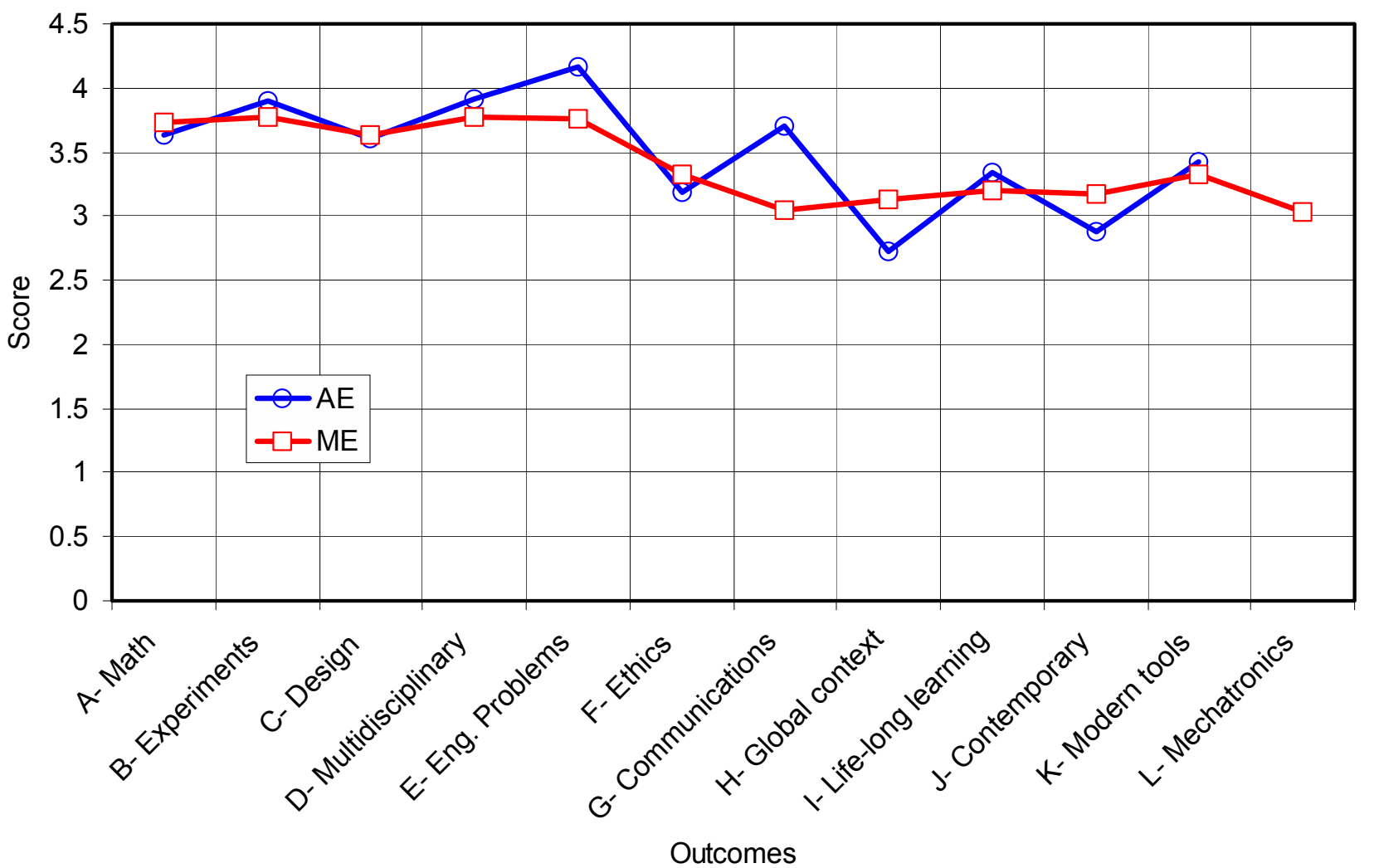

Figure 3. Comparison of AE and ME outcome assessment calendar year 2002.

$$
\begin{aligned}
& 0 \\
& 00 \\
& 0 \\
& 0 \\
& 0 \\
& 0 \\
& 0 \\
& \sigma \\
& \vec{\sigma}
\end{aligned}
$$

